\title{
Twelve year clinical study of patients with hypoxic cor pulmonale given long term domiciliary oxygen therapy
}

\author{
C B COOPER, J WATERHOUSE, P HOWARD
}

From the University Department of Medicine, Royal Hallamshire Hospital, Sheffield

ABSTRACT Patients presenting with chronic obstructive airways disease and hypoxic cor pulmonale were assessed during a period of clinical stability. Seventy two patients ( 53 male) with a mean age of 60 years were selected for long term oxygen therapy. Mean FEV 1 was 0.781 and forced vital capacity 1.91 . The mean arterial oxygen tension $\left(\mathrm{PaO}_{2}\right)$ was $6.1 \mathrm{kPa}(46 \mathrm{~mm} \mathrm{Hg})$ and the mean arterial carbon dioxide tension $\left(\mathrm{PCO}_{2}\right) 6.9 \mathrm{kPa}(52 \mathrm{~mm} \mathrm{Hg})$. All patients had a $\mathrm{PaO}_{2}$ of less than $8.0 \mathrm{kPa}(60 \mathrm{~mm} \mathrm{Hg})$ and 57 patients had a $\mathrm{PCO}_{2}$ of more than $6.0 \mathrm{kPa}(45 \mathrm{~mm} \mathrm{Hg})$. Pulmonary haemodynamics were measured in 45 patients yielding the following mean values: pulmonary artery pressure $28.3 \mathrm{~mm} \mathrm{Hg}$; cardiac output $5.91 \mathrm{~min}^{-1}$; total pulmonary vascular resistance $59 \cdot 2 \mathrm{kPa}^{-1} \mathrm{~s}$. Oxygen delivery systems, including 23 oxygen concentrators, were installed in the patients' homes. Flow rates were adjusted to raise $\mathrm{PaO}_{2}$ to more than $8.0 \mathrm{kPa}(60 \mathrm{~mm} \mathrm{Hg})$ for at least 15 hours each day and close supervision was maintained. Overall five year survival was $62 \%$, which is better than previously reported for this type of patient; but the 10 year survival was only $26 \%$ owing to an observed acceleration in death rate at about this time. Progressive disturbances of the pulmonary circulation were arrested. Mortality was associated with the severity of airflow obstruction, reflecting a continuing pathological process affecting the airways.

Survival is poor in patients with cor pulmonale complicating chronic obstructive airways disease. ${ }^{1-5}$ The benefits of long term oxygen therapy in these patients were examined in the nocturnal oxygen therapy (NOT) trial ${ }^{6}$ and the report of the Medical Research Council Working Party (MRC). ${ }^{5}$ In the MRC study survival in women appeared to be better than in men, although the female group was small and hence few deaths occurred during the period of follow up. In men the benefit of long term oxygen therapy on survival was not apparent until about 500 days, a delay that has never been adequately explained. The five year survival in men was $42 \%$. The mean duration of follow up in the NOT trial was 19 months. The projected three year survival in the group having continuous oxygen therapy was $63 \%$. Timms et al have recently reviewed the data from the NOT trial and report that survival up to eight years is related to the fall in mean pulmonary artery pressure during the first six months of long term oxygen therapy. Survival in

\footnotetext{
Address for reprint requests: Dr C B Cooper, University Department
} of Medicine, Royal'Hallamshire Hospital, Sheffield S10 2JF.

Accepted 26 September 1986 the group treated with oxygen for 12 hours each day was correlated with pulmonary vascular resistance, but this relationship was not apparent for those having continuous oxygen therapy.

Our centre has a high incidence of cor pulmonale complicating chronic obstructive airways disease, ${ }^{8}$ and we have conducted a study over 12 years in patients given long term oxygen therapy. Now that expansion of domiciliary oxygen prescribing has gained the approval of the Department of Health and Social Security, ${ }^{9}$ it is important to identify those patients who are likely to benefit and to know what length of survival can be expected with this treatment. We have analysed survival and examined the prognostic value of some clinical characteristics.

\section{Methods}

The patients presented from 1971 to 1984 with a clinical diagnosis of chronic bronchitis and emphysema. Most were first encountered during an admission to hospital with an acute exacerbation of airflow obstruction associated with respiratory failure and oedema. After recovery they were assessed during 
several weeks of clinical stability. Those fulfilling the following criteria were included in the study: $(a)$ $\mathrm{FEV}_{1}$ less than $50 \%$ of predicted normal values ${ }^{10}$; (b) chronic hypoxaemia with an arterial oxygen tension $\left(\mathrm{PaO}_{2}\right)$ consistently less than $8.0 \mathrm{kPa}(60 \mathrm{~mm} \mathrm{Hg})$; and (c) at least one recorded episode of peripheral oedema as evidence of cor pulmonale. Patients unlikely to be compliant with long term oxygen therapy and those whose homes could not be adequately fitted and supplied with oxygen cylinders were excluded.

Physiological measurements were made on at least two occasions before the start of oxygen therapy and included age, height, weight, packed cell volume, $\mathrm{FEV}_{1}$, forced vital capacity (FVC), lung volumes determined by helium mixing, and carbon monoxide transfer factor (TLCo) determined by the single breath technique. Blood gas tensions were measured while patients were breathing air and after two hours of breathing $30 \%$ oxygen. Many patients underwent right heart catheterisation, a balloon tipped flow directed catheter (Swan Ganz) being introduced via an antecubital vein. Mean pulmonary artery pressure was recorded with a transducer (SE Laboratories 648) and cardiac output was calculated by the Fick equation or by the thermal dilution method. Total pulmonary vascular resistance was calculated on the assumption of a left atrial pressure of zero. Pulmonary haemodynamics were measured again after 12-18 months of long term oxygen therapy.

Seventy two patients were included. Twenty two used oxygen concentrators at some stage during the study and the rest were supplied by regular deliveries of $G(3600$ l) or F (1360 l) size cylinders. A special maintenance and breakdown service ensured an uninterrupted supply of oxygen and those patients using cylinders were taught to change the reducing valves themselves. Oxygen was given by nasal prongs and the flow rate $\left(1.5-2.51 \mathrm{~min}^{-1}\right)$ was regulated to maintain the $\mathrm{PaO}_{2}$ at more than $8.0 \mathrm{kPa}(60 \mathrm{~mm} \mathrm{Hg})$ during treatment. Patients were instructed to use the system overnight and for at least 15 hours in every 24 hours. Close supervision of patients is necessary to achieve the best compliance ${ }^{11}$; so the patients were reassessed in hospital every three months and monitored by home visits during the intervals. Serial blood gas tensions were measured every two to three months, in hospital and at home, to confirm that the response to treatment was maintained.

Oedema was controlled by diuretic treatment, fluctuations of chronic obstructive airways disease were treated with $\beta_{2}$ sympathomimetic bronchodilators and occasionally with sustained release methylxanthines. Infections were usually treated with ampicillin or amoxycillin. All patients were discouraged from smoking during the study but it was clear from carboxyhaemoglobin measurements that some continued to do so. The amount smoked by individual $\vec{\sigma}$ patients could not be accurately assessed and it was not possible to make a reliable separation of patients into smokers and non-smokers for the purpose of $\frac{\varnothing}{2}$ further analysis. We were unable to determine the direct influence of smoking on survival.

The recruitment of patients was evenly distributed $\vec{\circ}$ throughout the study and the median duration of fol- $\overrightarrow{\vec{\omega}}$ low up was 5 years. Life tables were derived from $\vec{\omega}_{\sigma}$ fitting Cox's proportional hazards model. ${ }^{12}$ Subgroup survival was compared using the Lee Desu statistic. ${ }^{13} \times$ Association of clinical characteristics with survival $\stackrel{t}{N}$ was examined by the $\chi^{2}$ likelihood ratio test. A p value ? less than 0.05 was considered significant.

\section{Results}

Since 1971 in Sheffield 72 patients $\left(53\right.$ men and $19 \stackrel{\frac{1}{O}}{\circ}$ women) have received domiciliary oxygen therapy according to the selection criteria. Thirty five reported that they were ex-smokers and 37 admitted that they $\vec{\bullet}$ continued to smoke. Their clinical characteristics are $\stackrel{0}{V}$ shown in table 1 . While they were breathing oxygen (inspired oxygen concentration $30 \%$ ) the mean $\mathrm{PaO}_{2}$ increased from 6.1 to $9.1 \mathrm{kPa}$ (a mean increase of $3.0 \mathrm{kPa}$ ) while the mean arterial carbon dioxide tension $\left(\mathrm{PaCO}_{2}\right)$ increased from 6.9 to $7.3 \mathrm{kPa}$ (a mean $\stackrel{0}{\varnothing}$

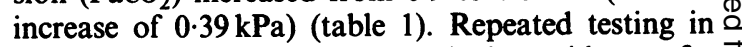
hospital and at home gives convincing evidence of a $\overrightarrow{\vec{O}}$ sustained increase in $\mathrm{PaO}_{2}$ in patients having domicil- 3 iary oxygen therapy. ${ }^{11}$

Pulmonary artery catheterisation was carried out in 45 patients before entry into the study and was repeated in 40 patients after 12 months of long term $\frac{0}{2}$ oxygen therapy. The values for pulmonary artery $x$

Table 1 Clinical characteristics of the 72 patients (53 male, 19 female) starting domiciliary oxygen therapy (mean values with standard deviations in parentheses)

\begin{tabular}{|c|c|}
\hline $\begin{array}{l}\text { Age (y) } \\
\text { Weight (kg) } \\
\text { FEV (l) } \\
\% \text { Pred FEV } \\
\text { FVC (l) } \\
\text { TLC (l) } \\
\text { RV/TLC (\%) } \\
\left.\text { TLCO (mmol min }{ }^{-1} \mathrm{kPa}^{-1}\right) \\
\mathrm{PaO}_{2}(\text { air) }(\mathrm{kPa}) \\
\mathrm{PaCO}_{2}(\text { air) }(\mathrm{kPa}) \\
\mathrm{PaO}_{2}\left(\mathrm{O}_{2}\right)(\mathrm{kPa}) \\
\mathrm{PaCO}_{2}\left(\mathrm{O}_{2}\right)(\mathrm{kPa}) \\
\operatorname{PCV}(\%)\end{array}$ & $\begin{array}{l}60 \cdot 5(7 \cdot 5) \\
68 \cdot 5(15 \cdot 0) \\
0.78(0 \cdot 31) \\
29(10) \\
1.90(0.64) \\
5.65(1.36) \\
60(10) \\
3.48(1.87) \\
6 \cdot 1(1 \cdot 0) \\
6.9(1 \cdot 2) \\
9 \cdot 1(1.4) \\
7 \cdot 3(1.4) \\
52(7)\end{array}$ \\
\hline
\end{tabular}

Conversion: SI to traditional units-Gas tensions: $1 \mathrm{kPa}=0$ 7.5 mm Hg; TLCO: $1 \mathrm{mmol} \mathrm{min}^{-1} \mathrm{kPa}^{-1}=2.99 \mathrm{ml} \mathrm{min}^{-1} \mathrm{~mm} \mathrm{Hg}^{-1} \bar{O}$ FVC-forced vital capacity; TLC-total lung capacity; RVresidual volume: TLCO-carbon monoxide transfer factor $\bigcap_{\text {}}$ $\mathrm{PaO}_{2}$-arterial oxygen tension; $\mathrm{PaCO}_{2}$-arterial carbon dioxide ten $\mathbb{D}$ sion; (air)-breathing air; $\left(\mathrm{O}_{2}\right)$-breathing oxygen; PCV-packed cell volume. 
Table 2 Pulmonary haemodynamics (mean values with standard deviations in parentheses)

\begin{tabular}{lll}
\hline & Before treatment & After 12 months \\
\hline PAP (mm Hg) & $28 \cdot 3(10 \cdot 2)$ & $26 \cdot 1(11 \cdot 0)$ \\
Cardiac output $\left(1 \mathrm{~min}^{-1}\right)$ & $\begin{array}{l}(\mathrm{n}=45) \\
(\mathrm{n}=9(1 \cdot 8)\end{array}$ & $\begin{array}{l}(\mathrm{n}=40) \\
(\mathrm{n}=3 \cdot 8)\end{array}$ \\
TPVR (kPa $\left.{ }^{-1} \mathrm{~s}\right)$ & $\begin{array}{l}59 \cdot 2(25 \cdot 3) \\
(\mathrm{n}=42)\end{array}$ & $\begin{array}{l}\mathrm{51} \cdot 1(24 \cdot 7) \\
(\mathrm{n}=37)\end{array}$
\end{tabular}

Conversion: SI to traditional units-TPVR: $1 \mathrm{kPa}^{-1} \mathrm{~s}=6.809$ dynes

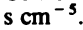

PAP-mean pulmonary arterial pressure; TPVR - total pulmonary vascular resistance.

pressure, cardiac output, and total pulmonary vascular resistance were unchanged (table 2).

The cumulative survival proportions for the whole group of patients are shown in figure 1 . The survival proportions for normal subjects and untreated men in the MRC study ${ }^{5}$ have been plotted for comparison. The five year survival proportions for the three groups are $62 \%$ (patients in this study), $87 \%$ (normal subjects), and 16\% (MRC controls). The survival curves suggest that the benefit of long term oxygen therapy follows the start of treatment immediately. The 10 year survival for the patients was $26 \%$, indicating an acceleration in death rate at 10 years despite long term oxygen therapy. Thirty eight had died at the time of analysis (30 men, eight women).

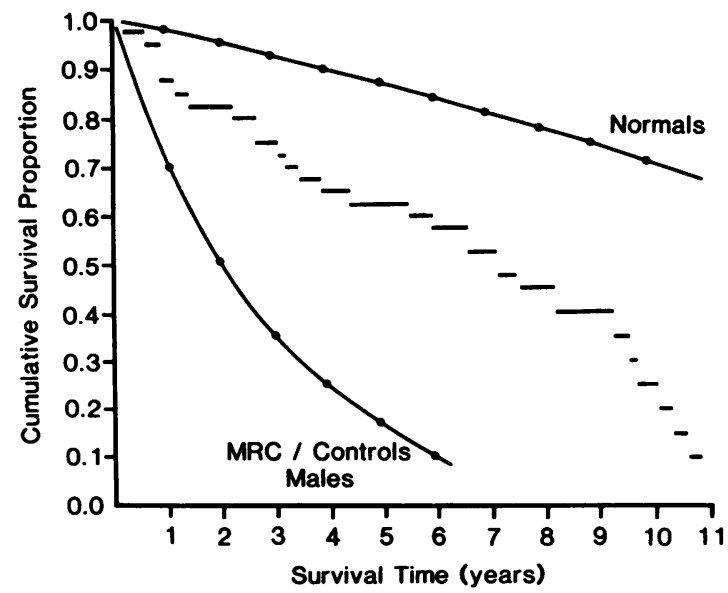

Fig 1 Life table for all patients having long term oxygen therapy. The predicted survival proportions for an exactly age and sex matched group of normal individuals have been derived from the English Life Table 1970-72, ${ }^{15}$ The survival of untreated men in the Medical Research Council study has been plotted by use of the calculated annual risk factor $29.4 \%$. $^{5}$

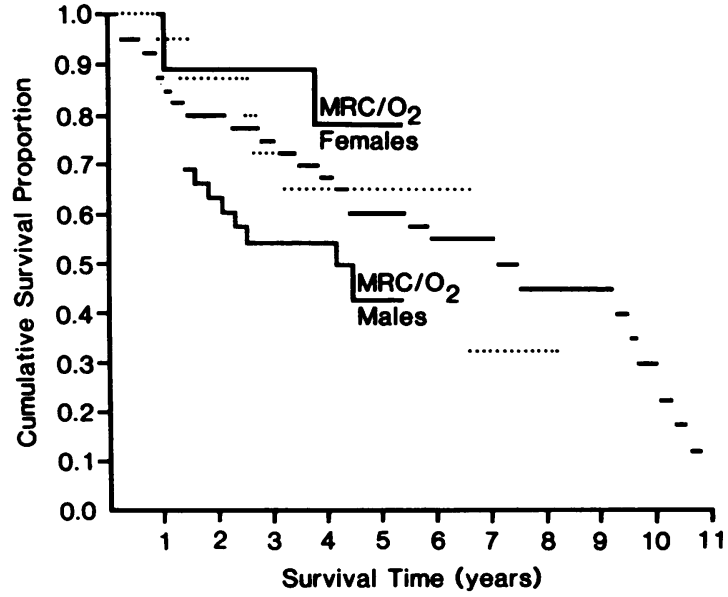

Fig 2 Life tables for patients having long term oxygen therapy according to sex, showing no difference in survival between men (-) and women (....). Survival curves of treated male and female groups in the Medical Research Council study are plotted for comparison.

Survival for males and females is plotted separately in figure 2. There was no difference in survival between the sexes $(p=0.583)$ and the survival curves lie between those of the treated male and female groups of the MRC study.

The association of various clinical characteristics with survival was analysed with a $\chi^{2}$ likelihood ratio test (table 3 ). Survival was clearly associated with indices of airflow obstruction $\left(\mathrm{FEV}_{1}: \mathrm{p}=0.019\right.$; FVC: $p=0.013$, whereas no association was observed with blood gas tensions during the breathing of air, the rise in $\mathrm{PaO}_{2}$ during the breathing of oxygen, pulmonary artery pressure or total pulmonary vascular resistance. When subgroups were compared, sur-

Table 3 Association of clinical characteristics at entry with survival of patients having long term oxygen therapy

\begin{tabular}{lll}
\hline Characteristic & $\chi^{2 *}$ & $p$ value \\
\hline Age & 1.213 & 0.271 \\
FEV & 5.551 & 0.019 \\
$\%$ Pred FEV $_{1}$ & 5.167 & 0.023 \\
FVC & 6.112 & 0.013 \\
$\mathrm{PaO}_{2}$ (air) & 1.217 & 0.270 \\
$\mathrm{PaCO}_{2}$ (air) & 0.386 & 0.534 \\
$\mathrm{PaO}_{2}\left(\mathrm{O}_{2}\right)$ & 1.155 & 0.283 \\
$\mathrm{PaCO}_{2}\left(\mathrm{O}_{2}\right)$ & 2.400 & 0.122 \\
PaO $_{2}$ & 0.004 & 0.953 \\
PAP & 1.578 & 0.209 \\
TPVR & 1.423 & 0.233
\end{tabular}

*Likelihood ratio test from fitting Cox's proportional hazards model. FVC-forced vital capacity; $\mathrm{PaO}_{2}$ - arterial oxygen tension; $\mathrm{PaCO}_{2}$-arterial carbon dioxide tension; (air)-breathing air; $\left(\mathrm{O}_{2}\right)^{2}$-breathing oxygen; $\triangle \mathrm{PaO}_{2}=\mathrm{PaO}_{2}\left(\mathrm{O}_{2}\right)-\mathrm{PaO}_{2}$ (air); PAPmean pulmonary artery pressure; TPVR - total pulmonary vascular resistance. 
vival was worse in patients with an FEV, below $30 \%$ predicted $(p=0.029)$, as shown in figure 3 , but not significantly different in those with a pulmonary artery pressure greater than $25 \mathrm{~mm} \mathrm{Hg}$ or a total pulmonary vascular resistance greater than $58 \cdot 8 \mathrm{kPa}^{-1} \mathrm{~s}\left(400\right.$ dynes $\left.\mathrm{s} \mathrm{cm}^{-5}\right)$.

\section{Discussion}

The patients in this study form a carefully selected group with severe airflow obstruction, hyperinflation, arterial hypoxaemia at rest, and impairment of gas transfer. All had experienced acute episodes of cor pulmonale. They entered the study in a stable hypoxaemic state, 57 remaining hypercapnic $\left(\mathrm{PaCO}_{2}>\right.$ $6.0 \mathrm{kPa}$ ).

Survival is considerably better than has previously been reported for hypoxic cor pulmonale in patients with similar degrees of airflow obstruction, hypoxia, and pulmonary hypertension (table 4). The five year survival without treatment is less than $40 \% .^{1-5}$ In a study of patients with hypoxic cor pulmonale given continuous oxygen therapy two year survival was $72 \% .{ }^{14}$ The predicted five year survival proportions for treated patients in the MRC and NOT trials were $53 \%(11.9 \%$ annual risk) and $39 \%$ (17.2\% annual risk overall). These figures compare with a five year survival in the present study of $62 \%(8.8 \%$ annual risk) and a 10 year survival of $26 \%$. The five year survival for an age and sex matched group of normal individuals is $87 \%$ according to English Life Tables 1970-1972. ${ }^{15}$ A selected group of patients with hypoxic cor pulmonale and oedema associated with chronic bronchitis and emphysema can expect a doubling of survival time as a result of long term oxygen therapy given for at least 15 hours each day. This conclusion is based on retrospective comparisons and therefore must be interpreted with caution. A change in the nature of the disease or general

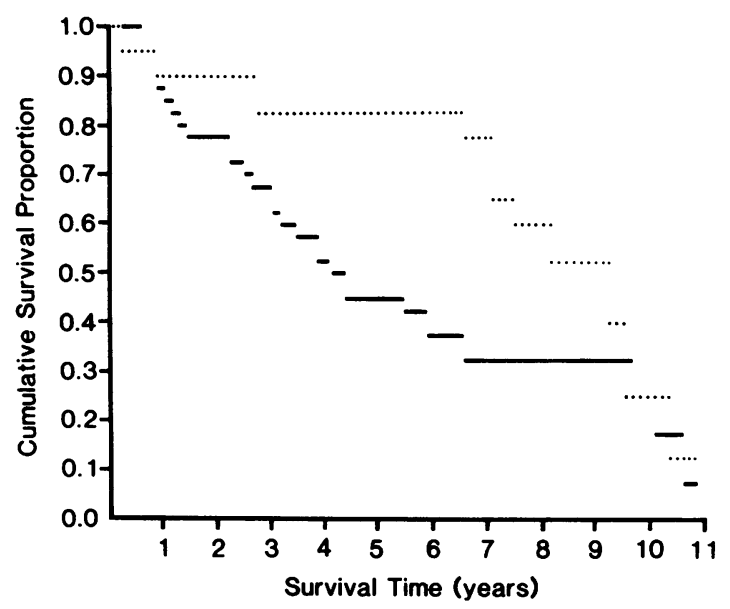

Fig 3 Life tables for patients having long term oxygen therapy according to severity of airflow obstruction.

Survival was better in those with an FEV $V_{1}$ of more than $30 \%$ of the predicted value (...) than in those with an $F E V_{1}$ of $30 \%$ or less $(-)(p=0.029)$.

improvement in management of the patients may have contributed to the fall in mortality that we observed. Nevertheless, these are the best survival figures so far reported in hypoxic cor pulmonale and provide justification for selecting this type of patient for long term oxygen therapy.

There are discrepancies with the results of the MRC study, ${ }^{5}$ which had similar patients. Five hundred days elapsed before benefit was apparent in men and this delay has never been explained. Our findings suggest, however, that the benefit of long term oxygen therapy is immediate, but clearly large numbers of patients and controls would be required to prove a significant difference in survival early after the start of oxygen therapy. The greater number of female patients has

Table 4 Survival proportions in hypoxic cor pulmonale

\begin{tabular}{|c|c|c|c|c|c|c|}
\hline & \multirow[b]{2}{*}{ Annual $\%$ risk } & \multicolumn{5}{|c|}{ Survival proportions $\%$} \\
\hline & & $I y$ & $2 y$ & $3 y$ & $4 y$ & $5 y$ \\
\hline $\begin{array}{l}\text { Controls } \\
\text { Stuart-Harris }(1957)^{1} \\
\text { Boushy and Coates }(1964)^{2} \\
\text { Renzetti et al }(1966)^{3} \\
\text { Ude and Howard }(1971)^{4} \\
\text { MRC, men }(1981)^{5} \\
\text { Oxygen } \\
\text { Neff and Petty }(24 \mathrm{~h})^{14} \\
\text { NOT trial }(12 \mathrm{~h})^{6} \\
\text { NOT trial }(24 \mathrm{~h})^{6} \\
\text { MRC, men }(15 \mathrm{~h})^{5} \\
\text { Present study }(15 \mathrm{~h})\end{array}$ & $\begin{array}{r}29.4 \\
20.6 \\
11.9 \\
11.9 \\
8.8\end{array}$ & $\begin{array}{l}76 \\
74 \\
64 \\
72 \\
71^{*}\end{array}$ & $\begin{array}{l}61 \\
58 \\
43 \\
52 \\
50^{*} \\
\\
72 \\
59 \\
78 \\
77^{*} \\
83\end{array}$ & $\begin{array}{l}53 \\
47 \\
32 \\
40 \\
35^{*}\end{array}$ & $\begin{array}{l}43 \\
39 \\
27 \\
40 \\
25^{*}\end{array}$ & $\begin{array}{l}37 \\
32 \\
32 \\
18^{*}\end{array}$ \\
\hline
\end{tabular}

*Predicted according to quoted annual risk factors.

NOT trial-Nocturnal Oxygen Therapy Trial. 
eliminated the apparent difference in survival between the sexes and emphasises that the female survival curve accompanies that of the males.

A 10 year survival of only $26 \%$ is disappointing and probably relates to a continuing pathological process that exerts its effect on airway function rather than in the pulmonary circulation. Survival for patients having long term oxygen therapy was clearly associated with indices of airflow obstruction but not with pulmonary artery pressure or total pulmonary vascular resistance. The prognostic value of $F V_{1}$ is recognised from large studies of patients with chronic obstructive airways disease ${ }^{216-18}$ and when FEV $_{1}$ falls below $450 \mathrm{ml}$ it contributes significantly to a poor prognosis. ${ }^{19}$ In severe hypoxic cor pulmonale without oxygen therapy progressive pulmonary hypertension becomes an important determinant of mortality, ${ }^{5720-22}$ and this may mask the relationship between $\mathrm{FEV}_{1}$ and survival. Acute administration of oxygen lowers pulmonary artery pressure ${ }^{23}$ and a fall greater than $5 \mathrm{~mm} \mathrm{Hg}$ has been associated with better survival for patients having long term oxygen therapy. ${ }^{24}$ The fall in pulmonary artery pressure can be sustained with long term oxygen therapy. ${ }^{25}$ In this study pulmonary artery pressure and total pulmonary vascular resistance were unchanged at the end of the first year of treatment in those who had haemodynamic measurements at this time and stabilisation of pulmonary artery pressure and total pulmonary vascular resistance was confirmed in some patients up to six years later. Long term oxygen therapy appears to interrupt the progression of haemodynamic disturbances, as was also observed in the MRC study, and in doing so has displaced the correlation of pulmonary hypertension with mortality.

There are two possible explanations. Long term oxygen therapy may prevent death from disturbances of the pulmonary circulation, so that mortality is then related to the continuing disease process in the airways and lung parenchyma. Alternatively, it is possible that the correlation of mortality with pulmonary hypertension is spurious, only masking important pathophysiological events elsewhere. The relevance of pulmonary hypertension has always been in doubt since the pulmonary artery pressure in chronic obstructive airways disease is usually considerably lower than in primary pulmonary hypertension, where right ventricular afterload leads to a fall in cardiac output to very low values. ${ }^{26}$ In hypoxic cor pulmonale cardiac output remains normal or is raised $^{27-29}$ and right ventricular function is only marginally impaired. ${ }^{3031}$ Failure to adapt by an increase in cardiac output leads to a reduction in oxygen delivery to the tissues and a fall in mixed venous oxygen tension, which has been associated with a poor survival rate. ${ }^{32}$ Unfortunately the beneficial effect of oxygen may be counterbalanced by a fall in cardiac output, so that oxygen delivery remains unchanged. Generally the measurement of pulmonary artery pressure in chronic obstructive airways disease is unhelpful but a detailed pathophysiological study of the airways and pulmonary circulation is needed in patients having long term oxygen therapy.

This study confirms that long term oxygen therapy is of benefit in carefully selected patients with hypoxic chronic obstructive airways disease. It is not yet clear whether it improves survival in hypoxic patients without oedema or in those with other forms of chronic respiratory disease. The analysis shows that there is no relationship between initial blood gas tensions and survival when hypoxia is subsequently corrected by long term oxygen therapy. Twenty nine of the 57 patients who were hypercapnic $\left(\mathrm{PaCO}_{2}\right.$ greater than $6.0 \mathrm{kPa}(45 \mathrm{~mm} \mathrm{Hg}))$ at entry died during the study but only three of the 15 normocapnic patients died. This suggests that chronic hypercapnia is associated with a poorer prognosis even though the five year survival in this subgroup was $59 \%$. Survival was better in patients who started long term oxygen therapy within two months of first developing oedema ( $p=0.039)$. This form of treatment should probably be considered in all hypoxic patients soon after the onset of oedema and before the development of severe hypercapnic respiratory failure. The proportion surviving after five years can be expected to double with long term oxygen therapy but the death rate accelerates at 10 years, indicating that the benefit is temporary. The progressive rise in pulmonary artery pressure is prevented and disturbances of the pulmonary circulation are no longer important determinants of survival. Mortality appears to be related to a continuing pathological process within the airways.

We thank Dr J P Nicholl for assisting with the statistical analysis and the staff of the respiratory function unit who have been concerned with the assessment of the patients.

\section{References}

1 Stuart-Harris CH, Hanley T. Chronic bronchitis, emphysema and cor pulmonale. Bristol: John Wright and Sons, 1957.

2 Boushy SF, Coates EO jun. The prognostic value of pulmonary function tests in emphysema: with special reference to arterial blood studies. Am Rev Respir Dis 1964;90:553-63.

3 Renzetti AD, McClement JH, Litt BD. The Veterans Administration Cooperative Study of Pulmonary Function III. Mortality in relation to respiratory function in chronic obstructive pulmonary disease. $\mathrm{Am} \mathrm{J}$ Med 1966;41:115-29. 
4 Ude AC, Howard P. Controlled oxygen therapy and pulmonary heart failure. Thorax 1971;26:572-8.

5 Medical Research Council Working Party. Long-term domiciliary oxygen therapy in chronic hypoxic cor pulmonale complicating chronic bronchitis and emphysema. Lancet 1981;i:681-6.

6 Nocturnal Oxygen Therapy Trial Group. Continuous or nocturnal oxygen therapy in hypoxemic chronic obstructive lung disease. Ann Intern Med 1980; 93:391-8.

7 Timms RM, Fareed UK, Williams GW. Nocturnal Oxygen Therapy Trial Group. Hemodynamic response to oxygen therapy in chronic obstructive pulmonary disease. Ann Intern Med 1985;102:29-36.

8 Williams BT, Nicholl JP. Prevalence of chronic obstructive lung disease with reference to long-term oxygen therapy. Lancet 1985;ii:369-72.

9 The Drug Tariff. Introduction of oxygen concentrators to the domiciliary oxygen therapy service. London: Department of Health and Social Security, 1986. (Publication No FPN 398.)

10 Cotes JE. Lung function. Assessment and application in medicine. 4th ed. Oxford: Blackwell Scientific Publications, 1979.

11 Evans TW, Waterhouse J, Howard P. Clinical experience with the oxygen concentrator. $\mathrm{Br} \mathrm{Med} J$ 1983; 287:459-61.

12 Cox DR. Regression models and life tables. $J \boldsymbol{R}$ Statist Soc B 1972;34:187-220.

13 Lee E, Desu M. A computer programme for comparing right-censored data. Computer Progams in Biomedicine 1972;2:315-21.

14 Neff TA, Petty TL. Long-term continuous oxygen therapy in chronic airway obstruction: mortality in relationship to cor pulmonale, hypoxia and hypercapnia. Ann Intern Med 1970;72:621-6.

15 Office of Population Censuses and Surveys. Life tables: the Registrar General's decennial supplement for 1970-1972. London: HMSO, 1979. Series DS No. 2.

16 Burrows B, Earle RH. Course and prognosis of chronic obstructive lung disease: a prospective study of 200 patients. N Engl J Med 1969;280:397-404.

17 Boushy SF, Thompson HK, North LB, Beale AR, Snow TR. Prognosis in chronic obstructive pulmonary disease. Am Rev Respir Dis 1973;108:1373-83.

18 Traver GA, Cline MG, Burrows B. Predictors of mortality in chronic obstructive pulmonary disease. $\mathrm{Am}$ Rev Respir Dis 1979;119:895-902.
19 Postma DS, Burema J, Gimeno F, et al. Prognosis in severe chronic obstructive pulmonary disease. Am Rev $\stackrel{\vec{D}}{\mathrm{C}}$ Respir Dis 1979;119:357-67.

20 Weitzenblum E, Loiseau A, Hirth C, Mirhorn R, Rasaholinjanahary J. Course of pulmonary hae- $\overline{\bar{c}}$ modynamics in patients with chronic obstructive pul- $\overparen{\mathbb{D}}$ monary disease. Chest 1979;75:656-62.

21 Weitzenblum E, Hirth C, Ducolone A, et al. Prognostic की value of pulmonary artery pressure in chronic obstruc- $\vec{O}$ tive pulmonary disease. Thorax 1981;36:752-8.

22 Bishop JM. Hypoxia and pulmonary hypertension in $\vec{\omega}$ chronic bronchitis. Progr Respir Res 1975;9:10-6.

23 Levine BE, Bigelow DV, Hamstra RD, et al. The role of $\overrightarrow{\vec{x}}$ long-term continuous oxygen adminstration in patients with chronic airways obstruction with hypox- ? emia. Ann Intern Med 1967;66:639-50.

24 Ashutosh K, Mead G, Dunksy M. Early effects of oxygen $\vec{\circ}$ administration and prognosis in chronic obstructive $G$ pulmonary disease and cor pulmonale. Am Rev Respir 윽 Dis 1963;127:399-404.

25 Stark RD, Finnegan P, Bishop JM. Long-term domicil- T iary oxygen in chronic bronchitis with pulmonary hypertension. Br Med J 1973;iii:467-70.

26 Hermiller JB, Bambach D, Thompson MJ, et al. Vasodilators and prostaglandin inhibitors in primary pul- $\overrightarrow{0}$ monary hypertension. Ann Intern Med 1982;97:480-9.

27 Burrows B, Kettel LJ, Niden AH, Rabinowitz M. Pat- . terns of cardiovascular dysfunction in chronic obstructive lung disease. $N$ Engl $J$ Med 1972;286:912-8.

28 Richens JM, Howard P. Oedema in cor pulmonale. Clin Sci Mol Med 1982;62:255-9.

29 Finlay M, Middleton HC, Peake MD, Howard P. Car- 음 diac output, pulmonary hypertension, hypoxaemia $\varrho$ and survival in patients with chronic obstructive air- $\overline{\bar{O}}$ ways disease. Eur J Respir Dis 1983;64:252-63.

30 Khaja F, Parker JO. Right and left ventricular performance in chronic obstructive lung disease. $A m$ 음 Heart J 1971;82:319-27.

31 Jezek V, Schrigen F, Sadoul P. Right ventricular function and pulmonary haemodynamics during exercise in patients with chronic obstructive bronchopulmonary disease. Cardiology 1973;58:20-31.

32 Kawakami Y, Kishi F, Yamamoto $\mathrm{H}$, Miyamoto $\mathrm{K}$. Relation of oxygen delivery, mixed venous oxygen- $O$ ation and pulmonary hemodynamics to prognosis in chronic obstructive pulmonary disease. $N$ Engl J Med 윽 1983;308:1045-9. 